\title{
Pharmacologic Atrial Natriuretic Peptide Reduces Human Leg Capillary Filtration
}

\author{
*Donald E. Watenpaugh, Susanne F. Vissing, Lynda D. Lane, Jay C. Buckey, \\ Brian G. Firth, William Erdman, *Alan R. Hargens, and C. Gunnar Blomqvist \\ University of Texas Southwestern Medical Center, Dallas, Texas, and ${ }^{*}$ Life Science Division, NASA Ames Research \\ Center, Moffett Field, California, U.S.A.
}

\begin{abstract}
Summary: Atrial natriuretic peptide (ANP) is produced and secreted by atrial cells. We measured calf capillary filtration rate with prolonged venous-occlusion plethysmography of supine healthy male subjects during pharmacologic infusion of ANP $(48 \mathrm{pmol} / \mathrm{kg} / \mathrm{min}$ for $15 \mathrm{~min} ; \mathrm{n}$ $=6)$ and during placebo infusion $(n=7)$. Results during infusions were compared to prior control measurements. ANP infusion increased plasma [ANP] from $30 \pm 4$ to $2,568 \pm 595 \mathrm{pmol} / \mathrm{L}$. Systemic hemoconcentration occurred during ANP infusion: mean hematocrit and plasma colloid osmotic pressure increased 4.6 and $11.3 \%$, respectively, relative to preinfusion baseline values $(\mathrm{p}<0.05)$. Mean calf filtration, however, was significantly reduced
\end{abstract}

from 0.15 to $0.08 \mathrm{ml} / 100 \mathrm{ml} / \mathrm{min}$ with ANP. Heart rate increased $20 \%$ with ANP infusion, whereas blood pressure was unchanged. Calf conductance (blood flow/ arterial pressure) and venous compliance were unaffected by ANP infusion. Placebo infusion had no effect relative to prior baseline control measurements. Although ANP induced systemic capillary filtration, in the calf, filtration was reduced with ANP. Therefore, pharmacologic ANP infusion enhances capillary filtration from the systemic circulation, perhaps at upper body or splanchnic sites or both, while having the opposite effect in the leg. Key Words: Extracellular fluid-Hemoconcentration-Capillary permeability-Capillary pressure.
Atrial natriuretic peptide (ANP) is a hormone produced and secreted by atrial myocytes on distention of the atria $(1,2)$. ANP is an established vasodilator, yet may also decrease blood pressure and cardiac output by reducing intravascular volume and cardiac filling pressure, because increases in hematocrit and plasma protein concentration are commonly associated with ANP administration (3). Furthermore, ANP-induced hematocrit elevation has been observed in nephrectomized animals $(4,5)$, and it occurs too quickly to be attributed solely to urinary loss. It seems that ANP somehow augments systemic filtration, or at least discourages reabsorption of extracellular fluid into the circulation.

Three studies have investigated effects of ANP on capillary filtration in the human forearm using prolonged venous-occlusion plethysmography. Two found that ANP increased forearm capillary filtration up to $63 \%(6,7)$, whereas the third showed only an insignificant trend toward elevation of fore- arm filtration (8). Using similar methods, we sought to determine whether ANP affects capillary filtration rate as measured in legs of human subjects; we hypothesized that ANP produces systemic hemoconcentration in part by increasing calf capillary filtration. We also attempted to relate effects on calf filtration rate to peripheral arteriolar or venous dilation or both, and to two systemic indices of hemoconcentration, hematocrit and plasma colloid osmotic pressure. The legs are important sites for study of capillary filtration because gravitational pressures in the circulation encourage leg filtration while upright, and because disease states such as congestive heart failure may be associated with supraphysiologic plasma [ANP] (1) and leg edema. Prolonged venous occlusion holds venous and capillary pressures relatively constant, which emphasizes effects of other Starling forces and permeability changes on capillary fluid movement. Conversely, effects of factors that alter filtration by 

changing capillary pressure cannot be assessed by this technique.

\section{METHODS}

\section{Subjects}

Ten healthy male subjects gave written, informed consent to participate. All were normotensive (arterial blood pressures $\leqslant 140 / 90$ ), unmedicated, did not use tobacco, and were not obese (life insurance tables). They were 24 to 47 years old (mean, 33 years), $180 \pm 3 \mathrm{~cm}$ tall (mean \pm $\mathrm{SEM}$ ), and they weighed $75.6 \pm 2.9 \mathrm{~kg}$. Female subjects were not recruited because of potential reproductive risks of radiation imposed by this research.

\section{ANP and placebo infusions}

We used synthetic 26 amino acid met-ANP provided by Merck, Sharp, and Dohme Research Laboratories. Lyophilized ANP was reconstituted in isotonic saline such that infusion of the resulting solution at $1.17 \mathrm{ml} / \mathrm{min}$ would deliver $48 \mathrm{pmol} \mathrm{ANP} / \mathrm{kg} / \mathrm{min}$ (150 ng/ $\mathrm{kg} / \mathrm{min}$ ) for 15 min to the subject. Placebo infusion consisted of an equal amount of isotonic saline $(17.6 \mathrm{ml}$ total). This research was approved by the UT Southwestern Human Research and Radiation Safety Committees, and by the U.S. Food and Drug Administration (Investigational New Drug number 30,392 ).

\section{Plasma ANP radioimmunoassay}

Atrial natriuretic peptide-like immunoreactivity in unextracted human plasma was measured with radioimmunoassay (RIA) kits purchased from Research and Diagnostic Antibodies, Inc., as previously described (9). Extraction is not called for by this RIA, and ANP measurement in unextracted plasma is a simpler technique with which we (9) and others (10) have had consistent and reliable results previously. Briefly, 7-ml blood samples were drawn into EDTA tubes after withdrawal of a 2-ml sample to avoid dilution of blood with the saline in the catheter. Blood was drawn from the arm before and at the end of control and infusion periods. The total volume of blood drawn during a study equaled $\sim 40 \mathrm{ml}$ and was replaced with an equal volume of isotonic saline. Chilled blood samples were centrifuged ( $20 \mathrm{~min}$ at $1,800 \mathrm{~g}$ ), and plasma aliquots were frozen at $-20^{\circ} \mathrm{C}$. Duplicate $100-\mu l$ thawed plasma samples were assayed according to the RIA kit instructions. The mean correlation coefficient for standard curves was 0.994 . Intra- and interassay coefficients of variation were 10.3 and $17.4 \%$, respectively. Percentage recovery by this RIA of ANP added to plasma samples averaged $83.1 \pm 7.2 \%$ (SEM) over a range from 1 to $7 \mathrm{fmol} \mathrm{ANP/tube.}$

\section{Resting calf blood flow and conductance}

Subdiastolic venous-occlusion plethysmography was employed with a Mercury-in-silastic strain gauge to measure calf blood flow. This method is well established and described in the literature (11). The strain gauge is placed around the point of maximum calf girth, and a pressure cuff is placed proximal to the knee. Inflation of the cuff to a subdiastolic pressure $(50 \mathrm{~mm} \mathrm{Hg}$ ) impedes venous drainage from the calf without affecting arterial inflow. Conductance is calculated by dividing flow by mean arterial pressure and provides an index of local vasodilation.

\section{Calf capillary filtration rate, blood volume, and vascular compliance}

Calf capillary filtration rate, blood volume, and vascular compliance were measured by combining venousocclusion plethysmography (to measure relative calf volume changes) with blood imaging $(99 \mathrm{~m})$ technetiumlabeled red blood cells (12) to measure relative calf blood volume $(13,14)$. Two $\mathrm{ml}$ of centrifuge-packed erythrocytes $(5 \mathrm{~min}$ at $1,300 \mathrm{~g}$ ) were labeled in vitro with $20 \mathrm{mCi}$ $99 \mathrm{mTc}$ according to instructions provided with the kit from Cadema Medical Products, Inc. (Middletown, NY, U.S.A.). Labeling of centrifuge-packed erythrocytes avoids undesirable and incidental labeling of plasma proteins. Before injection of the labeled erythrocytes, percentage binding of $\mathrm{Tc}$ to erythrocytes was quantified by recentrifuging an aliquot of the labeled sample in a microhematocrit centrifuge and then dividing gamma counts in the packed cells by counts in cells plus supernatant. Percentage of Tc bound to erythrocytes was always $>96 \%$ and usually $>98 \%$, thereby confirming minimal free and protein-bound Tc. Tc percentage binding remained at or above these levels in vivo. A Picker Digital Dyna Gamma Camera acquired images of both legs. Gamma counts were corrected for background and decay. One leg, determined at random, was instrumented for venousocclusion plethysmography, and the other served as an unoccluded control.

Plethysmographic calf volume increase during the rapid arterial inflow phase of venous occlusion (the first minute, when filtration is assumed to be negligible) calibrates the radionuclide blood volume technique $(13,14)$. Baseline calf blood volume percentage is calculated by applying the relationship between plethysmographic calfvolume elevation and gamma counts during the first minute of occlusion to the preocclusion gamma level (14). Prolonged venous occlusion consisted of $9 \mathrm{~min}$ at $50 \mathrm{~mm}$ $\mathrm{Hg}$. Calf vascular compliance was quantified as the increase in calf blood volume at $3 \mathrm{~min}$ of venous occlusion. Calf capillary filtration rate during venous occlusion equals elevation of plethysmographic calf volume minus the elevation of scintigraphic calf blood volume per unit time (i.e., rate of extravascular volume elevation). Calf filtration was quantified between 1 and $9 \mathrm{~min}$ of occlusion.

\section{Other dependent variables}

Heart rate was determined from ECG. A Narco Biosystems PE-300 electrosphygmomanometer indirectly measured brachial arterial blood pressure. Mean arterial pressure (MAP) was calculated as:

$$
\mathrm{MAP}=\mathrm{DBP}+[(\mathrm{SBP}-\mathrm{DBP}) / 3]
$$

We measured hematocrit of unoccluded arm venous blood with microhematocrit centrifugation. Plasma colloid osmotic pressure was measured in $100-\mu$ l samples with a membrane-exclusion colloid osmometer modified from Aukland and Johnsen (15). Samples were taken from those collected for ANP analysis. Plasma colloid osmotic pressure was not measured in the placebo group, because hematocrit did not change in that group (see Results).

\section{Protocol}

Subjects were instructed to abstain from caffeine, medications, and alcohol for at least $24 \mathrm{~h}$ before the study. All experiments were performed during mid-afternoon in the 
TABLE 1. Influence of ANP infusion on plasma [ANP], hemodynamics, plasma colloid osmotic pressure, and calf capillary filtration

\begin{tabular}{|c|c|c|}
\hline & Control & ANP \\
\hline ANP (pmol/L) & $30 \pm 4$ & $2568 \pm 595^{a}$ \\
\hline HR (beats/min) & $61 \pm 5$ & $73 \pm 6^{a}$ \\
\hline MAP (mm Hg) & $78 \pm 3$ & $77 \pm 3$ \\
\hline Calf blood volume (vol\%) & $4.7 \pm 0.8$ & $5.0 \pm 0.7$ \\
\hline $\begin{array}{l}\text { Conductance } \\
\left(\text { vol\% } 10^{2} / \mathrm{min} / \mathrm{mm} \mathrm{Hg}\right)\end{array}$ & $3.1 \pm 0.4$ & $3.8 \pm 0.4$ \\
\hline Compliance (vol $\% \cdot 10^{2} / \mathrm{mm}$ & & \\
\hline $\mathrm{Hg})$ & $3.0 \pm 0.2$ & $3.0 \pm 0.4$ \\
\hline Hematocrit (\%) & $43 \pm 1$ & $45 \pm 1^{a}$ \\
\hline $\begin{array}{l}\text { Plasma colloid osmotic } \\
\text { pressure }(\mathrm{mm} \mathrm{Hg})\end{array}$ & $21.7 \pm 0.6$ & $24.9 \pm 1.0^{a}$ \\
\hline Calf filtration (vol\%/min) & $0.15 \pm 0.03$ & $0.08 \pm 0.02^{a}$ \\
\hline
\end{tabular}

Vol\%, milliliters per $100 \mathrm{ml}$ tissue; ANP, atrial natriuretic peptide; HR, heart rate; MAP, mean arterial pressure.

Values reported as mean \pm SEM, $n=6$.

${ }^{a} \mathrm{p}<0.05$

Nuclear Medicine Division of Parkland Memorial Hospital, Dallas, Texas. Subjects were catheterized in an arm vein, after which they underwent the erythrocyte radiolabeling procedure. Subjects were then instrumented while supine with their legs elevated $\sim 15^{\circ}$ from horizontal (calves $15-20 \mathrm{~cm}$ above heart level, to facilitate emptying of leg veins) and knees slightly bent for comfort. Legs were supported with pillows and foam pads such that the calves were parallel to the gamma camera face and as close to it as possible without touching it. Subjects assumed this position $\sim 50$ min before the beginning of control data collection and remained so through the study. After completion of the control venous occlusion/data collection period (see Calf Capillary Filtration Rate, Blood Volume, and Vascular Compliance for details), a 20 -min period was allowed to ensure recovery from prolonged venous occlusion before beginning experimental data collection. The $9-\mathrm{min}, 50 \mathrm{~mm} \mathrm{Hg}$ venous occlusion for placebo or ANP data collection began 6 min after the onset of infusion, and infusion continued during venous occlusion (total infusion time $=15 \mathrm{~min}$ ). Subjects were awake during data collection.

\section{Statistical analyses}

Raw data were coded by one investigator and subsequently analyzed by another without access to identifying information. Paired $t$ tests delineated effects of placebo infusion $(\mathrm{n}=7)$ and ANP infusion $(\mathrm{n}=6)$ relative to prior baseline control results for each subject group. Three subjects were in both placebo and ANP groups. Independent two-tailed $t$ tests were employed to determine whether control data for the placebo and ANP subject groups were similar. In addition, correlation analysis determined significance of relationships between relevant variable pairs within protocol periods (16). ABstat procedures performed all statistical tests, with significance set at 0.05 (Anderson-Bell, Inc.). Results are expressed as means \pm SEM.

\section{RESULTS}

Intravenous infusion of ANP at $48 \mathrm{pmol} / \mathrm{kg} / \mathrm{min}$ for $15 \mathrm{~min}$ (a cumulative dose of $0.72 \mathrm{nmol} / \mathrm{kg}$ ) ele-

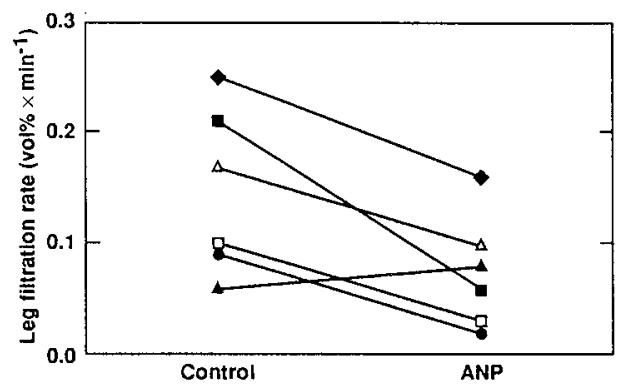

FIG. 1. Responses of individual subject's calf filtration rates to ANP infusion relative to control. Vol\% equals milliliters per $100 \mathrm{ml}$ tissue.

vated plasma ANP concentrations $\sim 85$-fold over preinfusion control levels (Table 1). This pharmacologic ANP infusion increased mean hematocrit 2 hematocrit units (\%) and mean plasma colloid osmotic pressure $3.2 \mathrm{~mm} \mathrm{Hg}$ relative to prior control values (Table 1). Mean capillary filtration rate in the calf, however, decreased $47 \%$ during ANP infusion. Individually, five of the six subjects who received ANP infusion exhibited a clear depression of calf filtration with ANP relative to preinfusion control values (Fig. 1). The single subject whose calf filtration increased with ANP had the lowest control value and was our oldest subject (47 years). Calf filtration related inversely with plasma colloid osmotic pressure during control data collection $\left(R^{2}=\right.$ 0.846 , Fig. 2), but this relationship became insignificant during ANP infusion $\left(R^{2}=0.484, \mathrm{p}=0.125\right)$.

ANP infusion tended to increase calf blood flow per unit arterial pressure (conductance) and also tended to increase preocclusion calf-blood volume, yet mean arterial pressure was unaffected by ANP (Table 1). Heart rate was elevated $20 \%$ during ANP infusion relative to prior control levels (Table 1). Calf conductance correlated positively with plasma [ANP] during preinfusion control periods in both ANP and placebo subject groups $(r=0.796$, Fig. 3). Calf venous compliance was unaffected by ANP infusion (Table 1). Control data for placebo and ANP

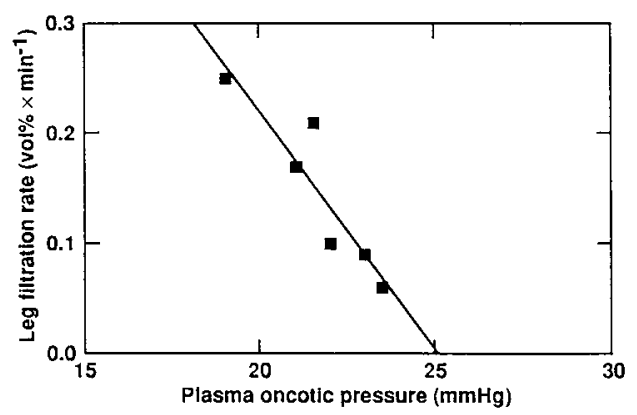

FIG. 2. Relationship between calf filtration rate and plasma colloid osmotic pressure during preinfusion control data collection in the six subjects who received ANP infusion. $R^{2}=$ $0.846, p=0.009$. Vol\% equals milliliters per $100 \mathrm{ml}$ tissue. 


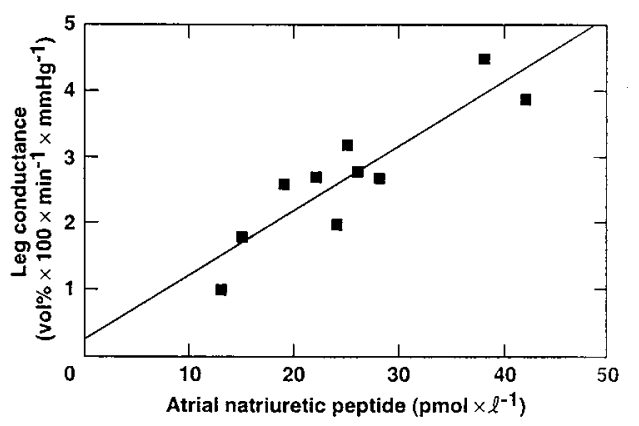

FIG. 3. Relationship between calf conductance and plasma [ANP] during preinfusion control data collection. Three subjects were in both placebo and ANP groups; data points for those subjects represent averages of data from their two control periods. $\mathrm{n}=10, R^{2}=0.634, \mathrm{p}=0.006$. Vol\% equals milliliters per $100 \mathrm{ml}$ tissue.

infusion groups were statistically similar. Placebo infusion had no effect on any variable relative to prior control measurements (Table 2).

\section{DISCUSSION}

Hematocrit and plasma colloid osmotic pressure findings confirm that a pharmacologic ANP stimulus produces hemoconcentration, in accordance with the literature $(1,3,17)$. Weidmann et al. (3) pointed out that ANP-induced hemoconcentration occurs more quickly than if diuresis were responsible. Our findings support their conclusion. A plasma volume reduction of $\sim 200 \mathrm{ml}$ occurred during the 15-min ANP infusion we employed (estimated from hematocrit increase, assuming blood volume of $\sim 5 \mathrm{~L} ; 5,9$ ). To excrete this volume over such a short time would require a urine production rate of $13 \mathrm{ml} / \mathrm{min}$, which is unlikely. We can conclude, therefore, that ANP enhanced fluid movement from plasma to interstitium in this study.

Although we expected ANP to increase leg capillary filtration in accordance with the systemic hemoconcentration we observed, the opposite actually occurred: ANP infusion reduced leg filtration. This observation disagrees with prior studies in the human forearm, which reported either enhanced filtration $(6,7)$ or a tendency toward such $(8)$ during ANP infusion. It is unlikely that differences in direction of response between this and earlier studies could be explained by differences in the peptides employed. Whereas one of the earlier studies did not report the ANP type used (6), the two other antecedent studies $(7,8)$ used 28 amino acid human (methionine) ANP. We used 26-amino acid human (methionine) ANP, which may be less potent than the larger peptide, yet exerts the same actions (1).

Under control conditions, subjects with greater plasma colloid osmotic pressures exhibited reduced calf capillary filtration (Fig. 2), as expected from
Starling's filtration equation $(18,19)$. Further increases in colloid osmotic pressure during ANP infusion would reduce subsequent occlusion-induced calf capillary filtration. However, no significant relationship existed between plasma colloid osmotic pressure and calf filtration during ANP infusion. The plasma colloid osmotic pressure increase we saw with ANP would reduce calf filtration only 0.02 vol\%/min with all else held constant, according to Starling's filtration equation $(18,19)$. Mean calf filtration actually decreased $0.07 \mathrm{ml} / 100 \mathrm{ml} / \mathrm{min}$. Groban et al. (6) noted ANP-induced elevation of forearm filtration despite significant increases in plasma protein concentration. Therefore, ANPinduced colloid osmotic pressure elevation cannot explain the depression of leg filtration we observed.

Fundamental differences may exist in upper and lower body filtration responses to ANP. It is possible that ANP enhances fluid transudation from the upper body or visceral microcirculation or both, while favoring reabsorption of interstitial fluid from the muscle and skin of the legs. This possibility seems reasonable in light of the biomechanical disadvantage cursorial organisms experience by adding weight to the leg (20). Other differences exist between human lower and upper body circulation. For example, capillary basement membranes are thicker (21), and tissues (22) and veins (23) are less compliant in the lower body than in the upper body. However, resting forearm and leg capillary hydraulic conductance are similar, as measured with supine venous occlusion plethysmography (24). Baseline calf filtration values in our study agree well with values from the literature $(13,14,25,26)$.

Alternative mechanisms exist to explain elevated systemic and forearm filtration induced by ANP. First, increased capillary hydrostatic pressure would oppose the reabsorptive force generated by plasma proteins $(5,27,28)$. Second, increased capillary permeability to various extracellular fluid constituents, including protein, would favor capillary filtration (29-32). These mechanisms are not mutually exclusive and could occur separately or together in specific vascular beds. Venous occlusion hypothetically holds capillary pressure constant. If

TABLE 2. Influence of placebo infusion on plasma [ANP], hemodynamics and calf capillary filtration

\begin{tabular}{lcc}
\hline & Control & Placebo \\
\hline ANP (pmol/L) & $21 \pm 2$ & $22 \pm 2$ \\
HR (beats/min) & $66 \pm 4$ & $68 \pm 4$ \\
MAP (mm Hg) & $88 \pm 4$ & $86 \pm 4$ \\
Calf blood volume $(\mathrm{vol} \%)$ & $3.8 \pm 0.5$ & $3.8 \pm 0.4$ \\
Conductance (vol\% $\left.\cdot 10^{2} / \mathrm{min} / \mathrm{mm} \mathrm{Hg}\right)$ & $2.4 \pm 0.3$ & $2.5 \pm 0.5$ \\
Compliance (vol\% $\left.\cdot 10^{2} / \mathrm{mm} \mathrm{Hg}\right)$ & $2.8 \pm 0.2$ & $2.6 \pm 0.4$ \\
Hematocrit (\%) & $44 \pm 1$ & $44 \pm 1$ \\
Calf filtration (vol\%/min) & $0.11 \pm 0.02$ & $0.09 \pm 0.01$ \\
\hline
\end{tabular}

ANP, atrial natriuretic peptide; vol\%, milliliters per $100 \mathrm{ml}$ tissue; $H R$, heart rate; MAP, mean arterial pressure.

Values reported as mean \pm SEM, $n=7, \alpha=0.05$. 
ANP increases filtration by elevating capillary pressure, then it should be rendered ineffective during venous occlusion. If, however, the peptide acts by increasing capillary permeability, then ANP should necessarily increase occlusion-induced filtration $(6,7)$. Our results, therefore, suggest that ANP actually reduces capillary permeability in the legs, while increasing it elsewhere.

ANP infusion often increases heart rate $(1,17,33)$. Most investigators view this finding as a reflexive response to ANP-induced systemic hypotension, because no direct chronotropic (or inotropic) effects of ANP have been conclusively identified ( 1 , $3,34)$. The positive relationship we observed between plasma [ANP] and calf conductance during the control period (Fig. 3) suggests that ANP contributes to calf vasomotor control in supine resting conditions. An increase in calf conductance during ANP infusion, such as we saw evidence of, is indicative of arteriolar vasodilation, which should reduce blood pressure. We may not have observed a reduction in blood pressure with ANP as compared to control because the cardiac arm of the carotid baroreflex defended an already low mean arterial pressure. (The control MAP mean was $78 \mathrm{~mm} \mathrm{Hg}$.)

In summary, we confirmed that a pharmacologic ANP dose produces hemoconcentration in normal human males, and that because it occurs so quickly, this hemoconcentration cannot be solely attributed to urine production. In spite of this evidence that ANP does indeed stimulate net movement of fluid out of the systemic circulation, calf capillary filtration during venous occlusion was reduced by ANP infusion. Because venous occlusion "clamps" capillary pressure, we conclude that pharmacologic ANP administration reduces capillary permeability in legs of supine human males.

Acknowledgment: We gratefully acknowledge Merck, Sharp, and Dohme Research Laboratories for supplying ANP, Chuck Graham and Dr. Geri Meny for technical support, our research subjects for their interest and cooperation, Drs. Richard Grindeland, Shigeyo Torikoshi, and Charles Wade for comments on the manuscript, and Carolyn Donahue and Karen Hutchinson for manuscript preparation.

This research was supported by a National Aeronautics and Space Administration Graduate Student Researchers Program Fellowship to DEW (NGT-50206), by other NASA grants to CGB (NAS 9-16044) and JCB (NAG 9-267), and by grants to SFV from the Danish Medical Research Council (12-6945 and 12-7663) and the Danish Heart Foundation.

\section{REFERENCES}

1. Brenner BM, Ballermann BJ, Gunning ME, Zeidel ML. Diverse biological actions of atrial natriuretic peptide. Physiol Rev 1990;3:665-99.

2. Christensen G. Cardiovascular and renal effects of atrial natriuretic factor. Scand J Clin Lab Invest 1993;53:203-9.
3. Weidmann P, Hellmueller B, Uehlinger DE, et al. Plasma levels and cardiovascular, endocrine, and excretory effects of atrial natriuretic peptide during different sodium intakes in man. J Clin Endocrinol Metab 1986;62:1027-36.

4. Fluckiger JP, Waeber B, Matsueda G, Deleloye B, Nussberger J, Brunner HR. Effect of atriopeptin III on hematocrit and volemia of nephrectomized rats. Am J Physiol 1986; 251:H880-3.

5. Trippodo NC, Barbee RW. Atrial natriuretic factor decreases whole-body capillary absorption in rats. Am J Physiol 1987;21:R915-20.

6. Groban L, Cowley AW, Ebert TJ. Atrial natriuretic peptide augments forearm capillary filtration in humans. Am J Physiol 1990;259:H258-63.

7. Ando S-I, Imaizumi T, Harada S, Hirooka Y, Takeshita A. Atrial natriuretic peptide increases human capillary filtration and venous distensibility. J Hypertens 1992;10:451-7.

8. Doorenbos CJ, Blauw GJ, van Brummelen P. Arterial and venous effects of atrial natriuretic peptide in the human forearm. Am J Hypertens 1991;4:333-40.

9. Watenpaugh DE, Yancy CW, Buckey JC, Lane LD, Hargens AR, Blomqvist CG. Role of atrial natriuretic peptide in systemic responses to acute isotonic volume expansion. $J$ Appl Physiol 1992;73:1218-26.

10. Ogihara T, Shima J, Hara H, Kumahara Y, Kangawa K, Matsuo $\mathrm{H}$. Changes in human plasma atrial natriuretic polypeptide concentration in normal subjects during passive leg raising and whole-body tilting. Clin Sci (Lond) 1986;71:14750 .

11. Whitney RJ. The measurement of volume changes in human limbs. J Physiol 1953;121:1-27.

12. Powell MR, Anger HO. Blood flow visualization with the scintillation camera. J Nucl Med 1966;7:729-32.

13. Schnizer W, Klatt J, Baeker H, Rieckert H. Comparison of scintigraphic and plethysmographic measurements for determination of capillary filtration coefficient in human limbs. Basic Res Cardiol 1978;73:77-84.

14. Vissing FS, Nielsen SL. Regional blood volume in man determined by radiolabeled erythrocytes. Clin Physiol 1988;8: 303-8.

15. Aukland K, Johnsen HM. A colloid osmometer for small fluid samples. Acta Physiol Scand 1974;90:485-90.

16. Zar J. Biostatistical analysis. Englewood Cliffs, New Jersey: Prentice-Hall, 1974.

17. Cody RJ, Atlas SA, Laragh JH, et al. Atrial natriuretic factor in normal subjects and heart failure patients. Plasma levels and renal, hormonal, and hemodynamic responses to peptide infusion. J Clin Invest 1986;78:1362-74.

18. Krogh A, Landis EM, Turner AH. The movement of fluid through the human capillary wall in relation to venous pressure and to the colloid osmotic pressure of the blood. J Clin Invest 1932;11:63-95.

19. Hargens AR, Cologne JB, Menninger FJ, Hogan JS, Tucker BJ, Peters RM. Normal transcapillary pressures in human skeletal muscle and subcutaneous tissue. Microvasc Res $1981 ; 22: 177-89$.

20. Bligh J. Locomotion. In: Environmental physiology of animals. New York: Halsted Press, chapter 8, 1976.

21. Williamson JR, Vogler NJ, Kilo C. Regional variations in the width of the basement membrane of muscle capillaries in man and giraffe. Am J Pathol 1975;63:359-67.

22. Kirsch KA, Merke J, Rambo N, Wicke HJ. Tissue compliance in superficial tissues along body axis in man. Pflugers Arch 1980;387:239-44

23. Watenpaugh DE, Breit GA, Ballard RE, Zietz S, Hargens AR. Vascular compliance in the leg is lower than that in the neck in humans [Abstract]. Med Sci Sports Exerc 1993;25: S26.

24. Gamble J, Gartside IB, Christ F. A reassessment of mercury in silastic strain gauge plethysmography for microvascular permeability assessment in man. J Physiol 1993;464:407-22.

25. Drury AN, Jones NW. Observations upon the rate at which 
oedema forms when the veins of the human limb are congested. Heart 1927;14:55-70.

26. Sejrsen P, Henricksen O, Paaske WP. Effect of orthostatic blood pressure changes upon capillary filtration-absorption rate in the human calf. Acta Physiol Scand 1981;111:287-91.

27. Vidal NA, Arranz CT, Mones Sias MC, Herrmann AP, Martinez Seeber A. Atrial natriuretic factor and body water distribution. Arch Int Physiol Biochim Biophys 1987;95:329-32.

28. Wijeyaratne CN, Moult PJA. The effect of $\alpha$ human atrial natriuretic peptide on plasma volume and vascular permeability in normotensive subjects. J Clin Endocrinol Metab 1993;76:343-6.

29. Huxley VH, Tucker VL, Verburg KM, Freeman RH. Increased capillary hydraulic conductivity induced by atrial natriuretic peptide. Circ Res 1987;60:304-7.

30. Williamson JR, Holmberg SW, Chang K, Marvel J, Sutera
SP, Needleman P. Mechanisms underlying atriopeptininduced increases in hematocrit and vascular permeation in rats. Circ Res 1989;64:890-9.

31. Baron DA, Lofton CE, Newman WH, Currie MG. Atriopeptin inhibition of thrombin-mediated changes in the morphology and permeability of endothelial monolayers. Proc Natl Acad Sci USA 1989;86:3397-8.

32. Lockette W, Brennaman B. Atrial natriuretic factor increases vascular permeability. Aviat Space Environ Med $1990 ; 61: 1221-4$.

33. Richards AM, Nicholls DG, Espiner EA, et al. Effects of alpha-human atrial natriuretic peptide in essential hypertension. Hypertension 1985;7:812-7.

34. Lappe RW, Todt JA, Wendt RL. Mechanism of action of vasoconstrictor responses to atriopeptin II in conscious SHR. Am J Physiol 1985;249:R781-6. 
